THE JOURNAL OF TEACHING ENGLISH FOR SPECIFIC AND ACADEMIC PURPOSES Vol. 7, No 3, 2019, pp. 303-309

UDC: 811.111:069 https://doi.org/10.22190/JTESAP1903303B

\title{
DEVELOPING ACADEMIC SKILLS IN BLENDED ENVIRONMENTS
}

\author{
Ana Balula $^{1}$, Sandra Vasconcelos ${ }^{2}$, António Moreira ${ }^{3}$ \\ 'Águeda School of Technology and Management - University of Aveiro, CIDTFF, Aveiro, Portugal; \\ ${ }^{2}$ School of Hospitality and Tourism, Polytechnic Institute of Porto, CIDTFF, Porto, Portugal; \\ ${ }^{3}$ Department of Education and Psychology - University of Aveiro, CIDTFF, Aveiro, Portugal \\ E-mail: ${ }^{1}$ balula@ua.pt, ${ }^{2}$ s.vanconcelos@esht.ipp.pt, ${ }^{3}$ moreira@ua.pt
}

\begin{abstract}
More teacher-centred in general, Higher Education Institutions are moving towards the incorporation of innovative and interactive practices and programmes, and in the last decades e-and b-learning have increasingly become credible alternatives to traditional modes of teaching and learning, and rethinking their curricula and strategies to incorporate e-approaches and digital technologies. The catalysts for this change thrive on the need to keep pace with other universities and recruiting students. The main goal of this paper is to briefly describe a PhD programme of the University of Aveiro, Portugal, and to put forward some selected blended strategies, namely concerning the use of digital technology to enhance learning and develop academic skills. Even though this paper does not directly address the topic of ESP, best practices described here are multi-disciplinary in nature, and offer insights as regards teaching practices and clues for academic and professional development and research on this topic.

Stemming from the definition of 'academic skills', several online teaching and learning strategies are described. We therefore focus our paper on three selected strategies, used in this $\mathrm{PhD}$ for developing project group-work, writing academic papers and presenting research to peers. We delve on three main academic skills (collaboration, writing and presentation), as they are the basis for meaningful and lifelong learning. These are transferable and extensive and rely on students' critical thinking and also on their team-work and initiative abilities, requiring them to be effective communicators and negotiators.

The PhD programme makes use of blended strategies and digital technology to enhance participants' learning experiences, sustaining the development of their academic skills. Students are required to participate in, produce and disseminate scientific research. Describing how different academic skills are developed throughout the PhD modules, the present text offers a fresh outlook on digital technology as a means of leveraging students' academic/research skills, putting forth practices that can be relevant for a wide variety of academic and professional domains. The program described is blended and offered in sequential subjects, allowing students to concentrate on a topic at a time and carry out more in-depth and focused research, integrating individual and collective knowledge. This structure and flexible delivery mode also meet the students' needs due to their professional obligations, promoting opportunities of continuous lifelong learning.

Regarding academic skills, by relying strongly on collaboration, interaction and peer feedback, the PhD fosters autonomous learning and critical thinking, offering students the opportunity to engage in networking and the development of interpersonal skills, which are crucial for their academic future, and closer to what will be expected from them in their professional lives.
\end{abstract}

Key words: academic skills, Doctoral Program on Multimedia in Education, blended learning, digital technologies

Submitted September $30^{\text {th }}, 2019$, accepted for publication November $2^{\text {ns }}, 2019$

@ 2019 by University of Nišs, Serbia | Creative Commons License: CC BY-NC-ND 


\section{INTRODUCTION}

Traditionally more centred on the teacher, teaching processes in Higher Education (HE) are gradually being updated to incorporate innovative and interactive practices and programmes. Leveraged by recent technological advancements and spurred on by a society that relies heavily on complex and apace-evolving information flows, these changes are reshaping the face of HE as we know it. Acting as catalysts for this change, over the last decades, e- and b-learning have, to an increasing extent, become reliable and sustainable alternatives to more traditional, face-to-face models, with more and more $\mathrm{HE}$ institutions rethinking their programs and overall strategies to incorporate these approaches.

The Technology Enhanced Learning and Societal Challenges (TELSC) program was first approved in 2014/15 and has been funded by the Portuguese Foundation for Science and Technology ever since. Aiming at promoting more open and innovative practices within the educational ecosystem, thus contributing to richer and more inclusive teaching and learning experiences, the TELSC consortium was founded on the concept of shared research and encourages participants to collaborate in the production and dissemination of original knowledge, both nationally and internationally. Thus, it substantiates a joint venture between three Portuguese universities, i.e. the University of Lisbon, the University of Minho and the University of Aveiro, having the latter proposed the integration of the Doctoral Program on Multimedia in Education (DPME), offered since 2008/09.

The main goal of this paper is to briefly describe the DPME, of the University of Aveiro in Portugal, and to put forward some selected blended strategies, namely concerning the use of digital technology to enhance learning and develop academic skills. Even though this paper does not directly address the topic of ESP, the best practices described are multi-disciplinary and can be of interest for experts and practitioners within this scope, providing them with foundations for practical teaching, possibilities of academic and professional development and related research.

\section{CONTEXT}

Deriving from a MA degree, also in Multimedia in Education, created in 2002, the DPME was created to give students the opportunity to further develop their research skills within Educational Sciences and Communication Sciences and Technologies. Due to the MA's success and based on previous evaluation panels, the model adopted for the DPME was blended learning, i.e. a hybrid approach combining face-to-face session with online activities. In the first editions of DPME, the platform used to support the modules was WebCT, which was then replaced by Blackboard, and currently by Moodle, although the programme has, for quite a few years, adopted less traditional CLMS technologies, namely those that allow for social networking and a wide variety of web tools and mobile apps.

DPME encompasses 7 different curricular units in the 1st year and, unlike most $\mathrm{PhD}$ curricular structures, they are not simultaneously ministered, making it easier for students to integrate their previous knowledge and competences in the following curricular units. They are generally organised in one-off 4-week modules (1-month long), distributed sequentially in time (see Figure 1). 


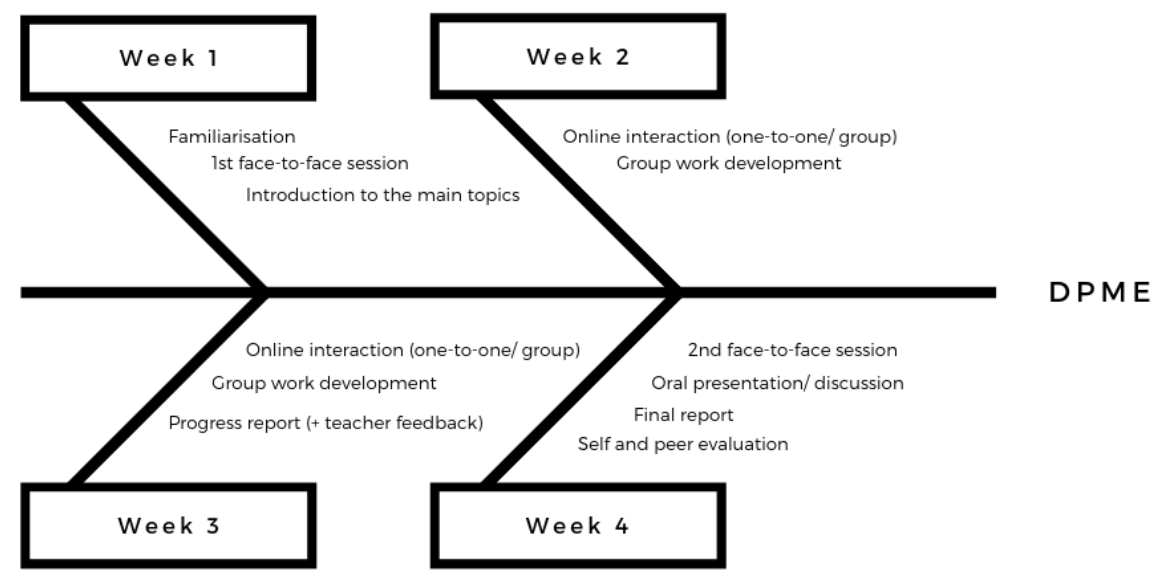

Fig. 1 DPME curricular units' structure.

Typically, the face-to-face sessions only occur in the first and last Monday of the modules (see Figure 1) and each module is divided into 3 different moments: i) familiarisation, ii) online interaction and iii) final assessment. Regarding familiarisation, it is always triggered by tasks proposed by the teacher in day one and which can translate, for instance, into asking students to interact in a discussion forum, i.e. to briefly present themselves and/or to discuss/comment on a specific topic/text, etc. The main goal of familiarisation is not only to get students to know each other and the teacher better, but also to introduce the main topics to be approached (using discussion forums/blogs/social networks), giving students the opportunity to prepare beforehand for the 1st face-to-face session and take the most out of it. In the 1st face-to-face session, besides discussing key concepts, students also organise into groups (preferably from different academic/ professional backgrounds) and draw a plan to address the group assignment. It is important to mention that groups tend to define/select different challenges, once it motivates information sharing and discussion between the groups.

The option for group work, instead of individual work, is not arbitrary; in fact, it is intended to lead students to develop teamwork skills, which may potentially result in more productive relationships and outputs. Regarding online interaction, it takes place during the following weeks and, in this time scope, students are expected to develop their group assignments online. Hence, besides the individual answer to questions posed by other participants in discussion forums/blogs/social networks, students are given the possibility to select/discuss the best tools to develop their group work. However, in specific cases, it is mandatory to use specific tools, such as: Wikis, Blogs (WordPress), Social bookmarking (Ma.gnolia, Delicious, Flickr, YouTube, etc.), Web 2.0 tools (Facebook, Ning, Twitter, etc.). Consequently, online interaction fosters the development of collaboration skills within the group and with other groups, a process in which the teacher adopts the role of tutor/facilitator.

Even though the option in DPME is to value the process of the students' learning over the product, the final assessment occurs in the 2nd face-to-face session and is seen as the culmination of each module, once students submit their final reports and are asked to present the results of their group work, which are to be commented on by the teacher and 
by their colleagues individually (oral peer review). Besides, in some cases, this is also the moment to take a written exam. At a first glance, it may seem that students' assessment is mostly concentrated on this last moment, but, in fact, they are informed from the beginning about all the items that are to be considered in the process, namely: i) feedback provided to issues raised by other participants (participation in discussion forums/blogs/ social netowrks); ii) a preliminary report, which is commented on and discussed with the teacher; iii) a final report, iv) an oral presentation (considering the peer review/discussion); and v) a written exam (optional). This structure and the strategies used throughout the course aim at fostering and enhancing interaction, collaboration, autonomous work and critical thinking, which are key skills for future researchers.

\section{PROMOTING ACADEMIC SKILLS}

First of all, it is important to define the concept of 'academic skills'. As Howard $(2012,73)$ clarifies, academic skills are transferable skills which underpin the learning of HE students, "enabling them to be confident, independent critical thinkers and reflective learners. (...) these skills comprise: finding and evaluating information; academic writing; reading and note-taking; preparing for exams; working in groups; presentation skills; referencing and avoiding plagiarism; time management; and critical thinking". In the DPME, the variety of online teaching and learning strategies designed for the different modules cross-cut several of the skills identified. In this paper, the focus is on three specific strategies, used effectively throughout the program and tailored to each module, namely: i) developing project work in groups, ii) writing academic papers, and iii) presenting research to peers, as described below.

\subsection{Academic collaboration skills}

Authors like Bozeman et al. 2001 and Lewis, Ross and Holden $(2012,695)$ point out that collaboration is a social activity that "relies on interpersonal networks - sets of interactions between individuals - which can take many forms". The DPME's pedagogical design embraces collaboration as one of its key pillars, since it has proven to enrich research outcomes and outputs, not only by leveraging critical reasoning through discussion, but also by capitalising on the participants' different prior knowledge to create more valuable, individual and collective new knowledge. As mentioned above, in every module, students are asked to develop a group project, with groups being reconfigured from module to module. Students know, from the beginning, that they will be held responsible for their individual learning, but they also play an important role in their group's and in the other groups' collective knowledge development. In fact, even though the groups' final work is an important piece in the participants' assessment, there are other elements that are taken into account, in particular the quality of the individual contribution to the group, as well as of the individual feedback that is given to questions posted by other students in discussion forums or blogs.

In one of the modules, the work structure is more complex, since the whole class is asked to develop a holistic project (project-based learning). It is based on authentic problems (taken from real work contexts), for which each group works upon a part of a wider problem, each group work becoming a piece of the final puzzle. In terms of dynamics, this implies the different groups have to interact and coordinate, establishing 
rapport with the other groups, negotiating and committing with solutions that fit the other groups' purposes to their own, in order to find a global answer for the initial challenge.

In another module, the groups are asked to design and implement a short online workshop, for which they have to define the topic, the pedagogic goals, the didactic approach, and the interaction and assessment strategies, as well as create the didactic materials. Given that it is very limited in time, this also implies the creation of guidelines for participants, so that they know from the start what is expected from them, e.g. which platforms are to be used and for what purpose; how and when participants are supposed to interact, etc. These workshops are then offered, with different groups acting as each other's students and testers, which makes for later discussions, based on both the course designers' and the participants' first hand experiences.

\subsection{Academic writing skills}

When it comes to academic writing, Horstmanshof and Brownie $(2013,62)$ underline that "learning to write in the appropriate academic style challenges students to acculturate by learning new conventions and acquiring new literacy skills. Included amongst these skills are argument development, critical interpretation, library research and appropriate referencing". Furthermore, it is also crucial to clearly and accurately select, justify and describe the methodological approach(es) of the research to guarantee the results' feasibility.

Thus, the development of academic writing proficiency is one of the most important presuppositions underlying the design of group work that students are expected to develop in the different modules. Throughout the seven modules, teachers expect students to perfect their academic writing skills and demonstrate them in their progress and final reports - e.g. by using specific, domain-related terminology; by demonstrating critical thinking and evidence-based argumentative skills, based on in-depth analyses of the literature; etc. In some modules, students are asked to use online writing tools to collaboratively write their reports. This is motivated by the fact that i) participants that were geographically distant can work on the same document, ii) there will be only one version of the document and students update their work more effectively, iii) it allows the teacher to be aware of the students' personal contributions.

Besides, in one of the modules, the experience is even more realistic, since the groups are asked to develop a literature review study, to be submitted to an existing research journal. After finishing their papers (in groups), they submit it through the regular channels and in compliance with the journals' rules. Their work publication is, therefore, subject to real peer review, which gives them the opportunity to grow as researchers and to be introduced to the peer review research process. In addition, students may also select the language in which the proposal is written (and some actually select English), allowing them to get feedback on their academic writing in English as a foreign language. Some examples of these papers are: University students develop employability skills in internship (available at https://proa.ua.pt/index.php/ilcj/article/view/1777/1411) and Scholars' YouTube channels: content analysis of educational videos (available at http://revistas.ua.pt/index.php/ilcj/article/view/1256). 


\subsection{Academic presentation skills}

It is widely accepted that "communication of results and new insights into our discipline are at the core of scientific publishing" (Chirik, 2017, 4339). In fact, when designing and carrying out research, practitioners should anticipate and carefully plan how to effectively disseminate their results, not only in terms of written publications, but also (and perhaps foremost) in different gatherings and conferences, in which they benefit from interacting and openly discussing ideas with their peers and other stakeholders. As Shi $(2013,406)$ underlines, "the ability to make powerful and effective oral presentations of research at international conferences is of great importance to researchers and research students. However, it is one of the most challenging competences to acquire for novice researchers and presenters".

Thus, the modules' design always includes a 15-minute oral presentation, which is open to discussion afterwards - similarly to what happens in research events. This activity promotes the improvement of their presentation and argumentative skills and is expected to influence their work in the following module, i.e. how they construct their individual and collective knowledge. In other words, the distribution of the oral presentations in time (see Figure 1) contributes towards delivering successful research-based oral presentations, as well as for validating/rethinking research options. Furthermore, students are also expected to do self and peer evaluation and, in some cases, are asked to evaluate the work presented by the other groups, giving them the opportunity to critically reflect upon their own learning, as well as that of their peers'.

\section{FinAL REMARKS}

The development of academic skills is key for tertiary education students, regardless of their learning and research areas, as they are the basis for meaningful and lifelong learning. These transferable and extensive skills rely heavily on students' critical thinking and their ability to work in teams and show initiative, which, in turn, requires them to be effective communicators and negotiators. In successful and relevant post-graduation programmes, these skills must be at the very core, and support content delivery, interaction, as well as individual and collective knowledge development.

In the scope of the TELSC programme, DPME is a PhD programme that makes use of blended strategies and digital technology to enhance participants' learning experiences and support the continuous development of their academic skills. Students enrolled in the programme are required to not only take part but also produce and disseminate scientific research. As a result, learning activities and strategies are adapted, moving beyond traditional spaces and platforms to incorporate not only a wide range of digital platforms, services and tools, but also new work methods, finding tailor-made solutions for their research challenges. In fact, the program embodies a different paradigm, in which participants are not only encouraged but expected to collaborate and come up with their own (individual and group) strategies to meet the challenges they are faced with.

Having listed different examples of how different academic skills are developed throughout the program's modules, this paper offers a fresh outlook on digital technology as a means of leveraging students' academic/research skills, putting forward best practices that can be relevant in a wide variety of fields. The fact that the program is blended and structured in sequential modules, though non-conventional, allows students 
to concentrate on a topic at a time and carry out more in-depth and focused research, integrating individual and collective knowledge from one module into the next. In addition, the structure and the flexible delivery mode also suits the target audiences' needs, namely working students, thus promoting opportunities of continuous lifelong learning.

On the other hand, regarding academic skills, by relying strongly on collaboration, interaction and peer feedback, the program fosters autonomous learning and critical thinking, also providing students with the opportunity to engage in networking and the development of interpersonal skills. These skills will be decisive for students' academic future, and are closer to what they are expected to master in their future professional lives.

\section{REFERENCES}

Bozeman, Barry, James Scott Dietz, and Monica Gaughan. "Scientific and technical human capital: an alternative model for research evaluation." International Journal of Technology Management 22, no. 7/8 (2001): 716-740.

Chirik, Paul J. "Organometallics in 2018." (2018): 271-272.

Horstmanshof, Louise, and Sonya Brownie. "A scaffolded approach to discussion board use for formative assessment of academic writing skills." Assessment \& Evaluation in Higher Education 38, no. 1 (2013): 61-73.

Howard, Helen. "Looking to the future: Developing an academic skills strategy to ensure information literacy survives in a changing higher education world." Journal of information literacy 6, no. 1 (2012): 72-81.

Jie, Shi, and Yoshimasa A. Ono. "Common errors in research presentation slides of Japanese graduate students." In 2016 International Conference on Advanced Mechatronic Systems (ICAMechS), 521-526. IEEE

Lewis, Jenny M., Sandy Ross, and Thomas Holden. "The how and why of academic collaboration: Disciplinary differences and policy implications." Higher Education 64, no. 5 (2012): 693-708. 